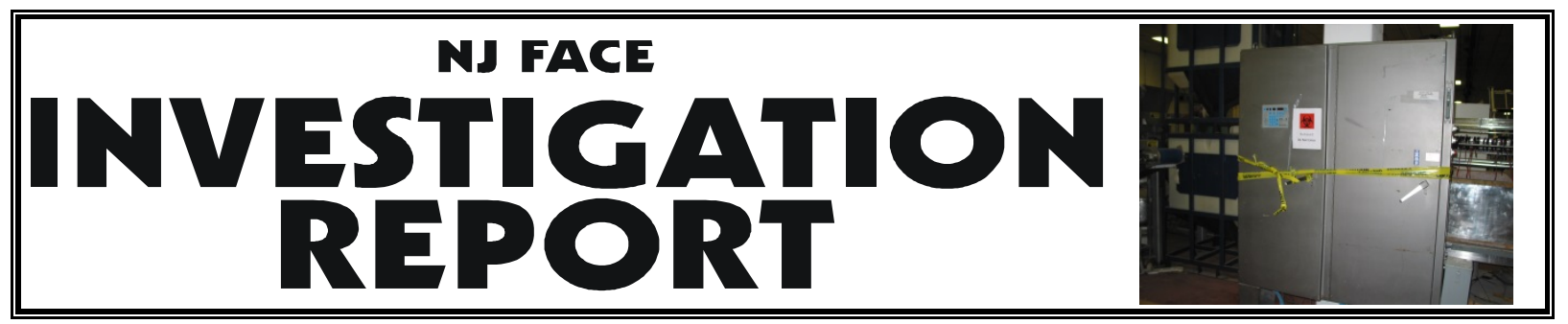

Fatality Assessment \& Control Evaluation Project

FACE 15-NJ-07

April 25, 2016

\title{
Mechanic Dies After Being Crushed Under Electrical Cabinet
}

A 62-year-old male mechanic died after being crushed by a 993.5-pound electrical cabinet he was working on tipped over. The incident occurred in a decommissioned equipment storage area of a frozen food manufacturing facility. On the day of the incident, the victim was removing salvageable equipment from a nonworking electrical cabinet, when it tipped over and crushed him between the floor and the cabinet. The victim died less than an hour later from compressional asphyxia combined with chest and cervical spine injuries.

Contributing Factors:

- $\quad$ Rusted/deteriorated leg supports

- Unit not anchored to wall

NJ FACE investigators recommend that these safety guidelines be followed to prevent similar incidents:

- A safety and health plan based on a job hazard analysis should be developed by the employer and followed where workers are assigned tasks.

- Prior to working on any object with a potential tipping hazard, proper support and structural integrity should be ensured.

- Any object with a potential tipping hazard should be adequately anchored to a permanently fixed point, such as wall or column.

Public Health Services Branch Division of Epidemiology, Environmental and Occupational Health Occupational Health Surveillance Unit (609) 826-4984 nj.gov/health/surv/face/index.shtml 
INTRODUCTION

In winter 2015, NJ FACE staff was notified of the death of a 62-year-old male mechanic who was killed after a 993.5-pound nonworking electrical cabinet he was working on tipped over. The incident occurred in a frozen food manufacturing plant in northern NJ. The victim had worked for the company for approximately 25 years.

An NJ FACE investigator contacted the OSHA Area Office and conducted a concurrent investigation. Additional information was obtained from the medical examiner's report, death certificate, and police report.

\section{INVESTIGATION}

The incident site was the decommissioned equipment storage area of a frozen food manufacturing plant located in northern NJ. The employer was a large food manufacturer with multiple locations; this specific plant's distribution was mostly the northeastern United States. Seventy-five permanent workers were employed at this location (10,000 employees world-wide). Food was prepared on site, frozen, boxed, and then shipped.

On the day of the incident, the victim arrived at 3:00 am for his shift. In addition to his normal duties as a mechanic, he was tasked with removing any salvageable parts from a large electrical cabinet. The cabinet measured 61-inches-wide, by 87-inches- high, by 12.5-inches-deep, and weighed 993.5 pounds (see Figure 1). The cabinet was located in a section of the plant reserved for storage of decommissioned equipment. The company had been recently sold, and the new owner decided to scrap all the equipment in this area. Employees were assigned to remove working parts to be used as possible replacement/spare parts for equipment still in service.

Near the end of his shift, the victim was working alone removing electrical circuit boards and other components from the cabinet. To reach some of the higher components inside the cabinet, he had to stand on the bottom shelf. Although there were no witnesses, it is believed (based on his position underneath the cabinet) that while he was standing on the bottom shelf and removing components, the cabinet tipped over and trapped him underneath as it crashed to the ground (Figure 2). The plant safety manager heard the noise of the crash and immediately ran over and, unsuccessfully, tried lifting the cabinet off the victim. He then radioed for help and five employees rushed to the scene. One employee called 9-1-1 while another drove a forklift over to help free the victim. The forks were placed under the electrical cabinet, two workers and the safety manger stabilized the cabinet on the forks while the other 
worker pulled the victim free. Two of the workers immediately began to administer CPR. Police and EMS arrived and the victim was transported to the hospital, where he was pronounced dead on arrival due to compressional asphyxia along with severe chest and spine injuries

FIGURE 1: Front view of electrical cabinet upright.



FIGURE 2. Incident scene; cabinet fell forward crushing the victim underneath.






\section{RECOMMENDATIONS/DISCUSSIONS}

Recommendation \#1: A safety and health plan based on a job hazard analysis should be developed by the employer and followed where workers are assigned tasks.

Discussion: Employers should conduct a job hazard analysis, with the participation of employees, of all work areas and job tasks. A job hazard analysis should begin by reviewing the work activities for which the employee is responsible, and the equipment that is needed. Each task is further examined for mechanical, electrical, chemical, or any other hazard the worker may encounter. In this case, it was observed by the police, OSHA, and FACE staff that the metal feet that supported the cabinet were rusted and had deteriorated (Figure 3). A thorough pre-task analysis may have revealed this issue and therefore could have prevented the incident. The analysis may also have revealed the need for a step ladder or stool for the worker to stand on (rather than the cabinet itself) to reach the higher sections of the cabinet. A source of information on conducting a job hazard analysis can be obtained from the US Department of Labor. $^{1}$

\section{FIGURE 3. Views of cabinet foot at incident scene.}
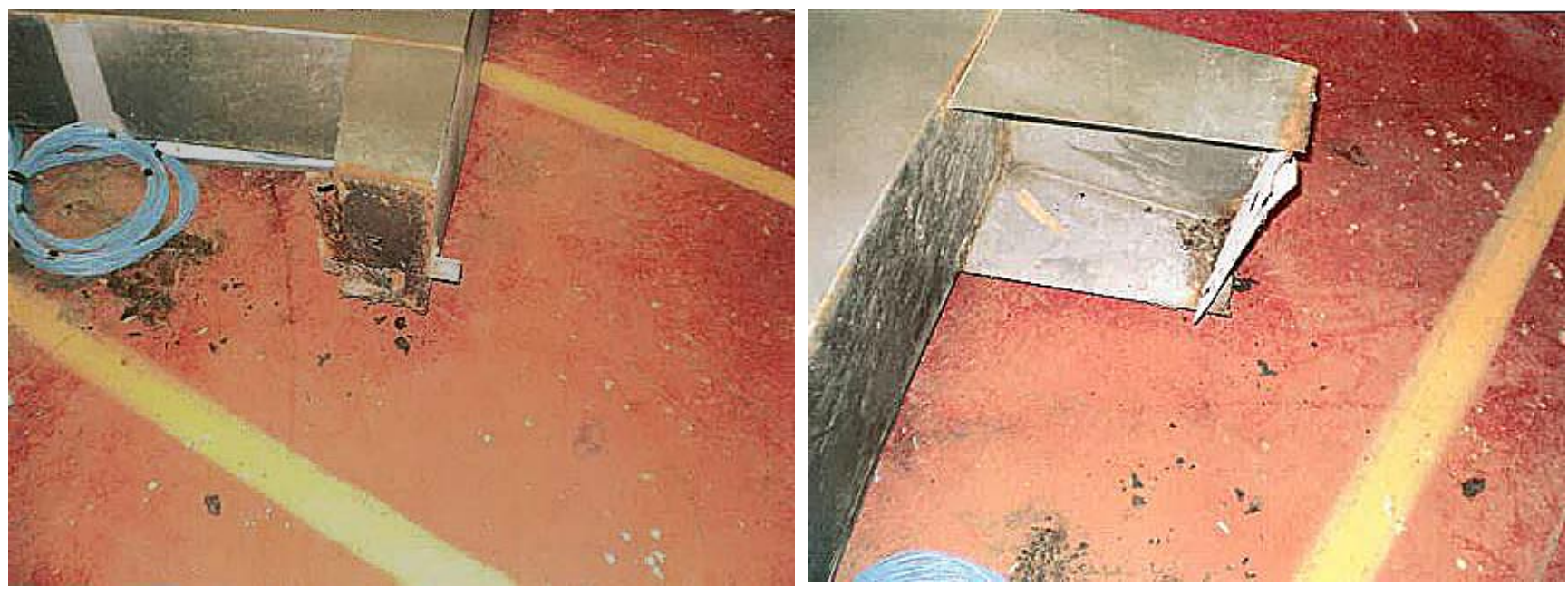

Recommendation \#2: Prior to working on any object with a potential tipping hazard, proper support and structural integrity should be ensured.

Discussion: As per 29 CFR 1910.176(b) (Materials Handling and Storage), storage of material should not create a hazard, and should be stable against sliding or collapse. ${ }^{2}$ As noted in Recommendation \#1 above, the metal feet that supported the cabinet were in poor condition. It is believed that when the victim was standing on the cabinet, the feet collapsed causing the unit to tip over. NJ FACE 
recommends that all structural components be inspected prior to starting work, especially if there is a potential tipping hazard.

\section{Recommendation \#3: Any object with a potential tipping hazard should be adequately anchored} to a permanently fixed point, such as wall or column.

Discussion: 29 CFR 1910.176(b) also notes that items should be secured against collapse. Any free standing object with the potential for tipping over should be anchored or attached to a wall or structural column. In this case, after the incident the employer secured the cabinet to a concrete column using a nylon strap attached to eye bolts affixed to the top of the cabinet (Figure 4). An in-line ratcheting nylon strap puller was used to tighten and maintain the tension on strap.

FIGURE 4. Electrical cabinet anchored to concrete column using nylon strap.

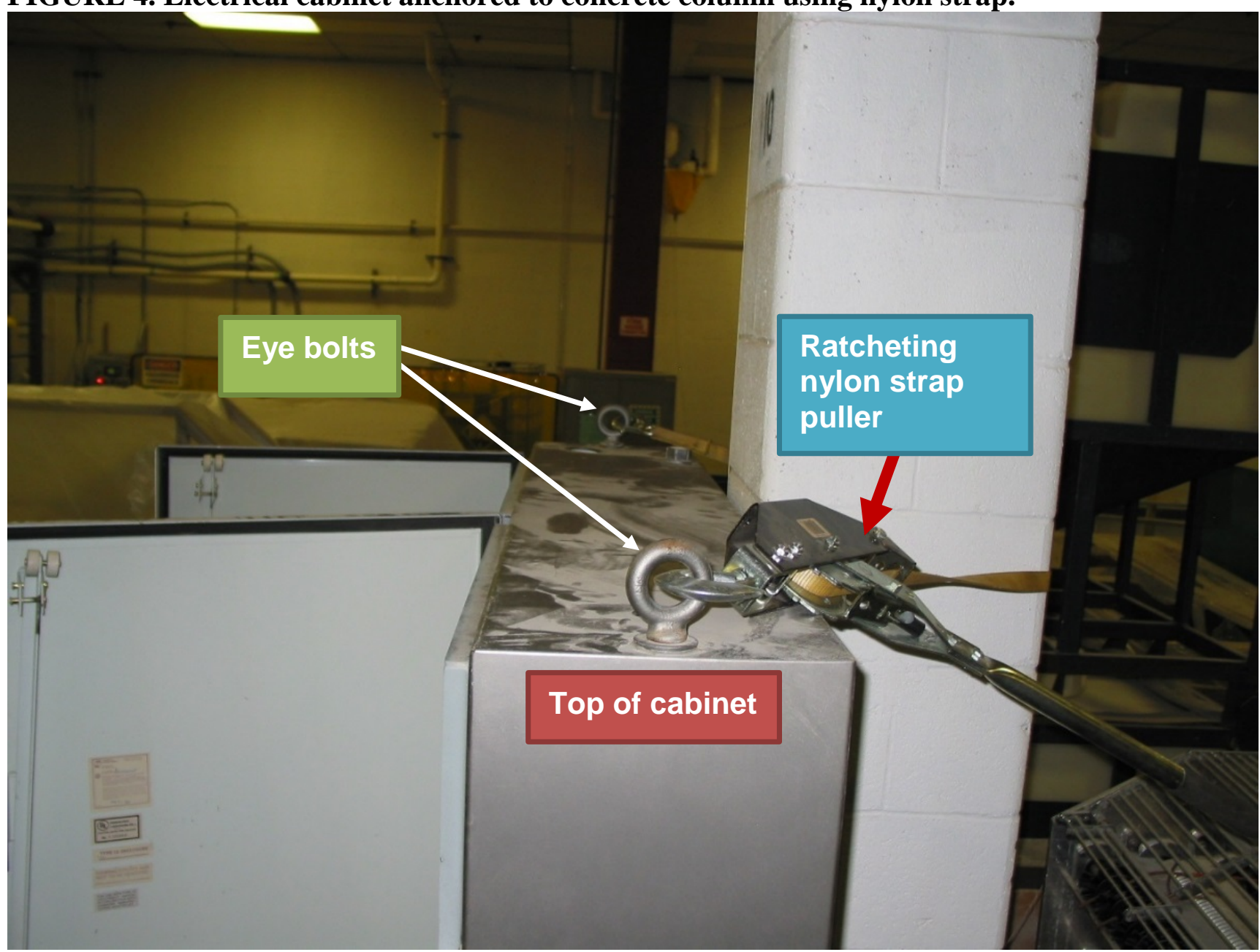




\section{APPENDIX}

\section{RECOMMENDED RESOURCES}

It is essential that employers obtain accurate information on health, safety, and applicable OSHA standards. NJ FACE recommends the following sources of information which can help both employers and employees:

\section{U.S. Department of Labor, Occupational Safety \& Health Administration (OSHA)}

Federal OSHA can provide information on safety and health standards on request. OSHA has several offices in New Jersey that cover the following counties:

留 Hunterdon, Middlesex, Somerset, Union, and Warren counties. $.732-750-3270$

Essex, Hudson, Morris, and Sussex counties. $.973-263-1003$

Bergen and Passaic counties. 201-288-1700

第 Atlantic, Burlington, Cape May, Camden, Cumberland, Gloucester,

Mercer, Monmouth, Ocean, and Salem counties. $856-596-5200$

Web site: $w w w . o s h a . g o v$

\section{New Jersey Public Employees Occupational Safety and Health (PEOSH) Program}

The PEOSH Act covers all NJ state, county, and municipal employees. Two state departments administer the Act: the NJ Department of Labor and Workforce Development (NJDLWD), which investigates safety hazards, and the NJ Department of Health (NJDOH), which investigates health hazards. PEOSH has information that may also benefit private employers.

NJDLWD, Office of Public Employees Safety

霩Telephone: 609-633-3896

Web site: www.nj.gov/labor/lsse/lspeosh.html

$\underline{\text { NJDOH, Public Employees Occupational Safety \& Health Program }}$

留 Telephone: 609-984-1863

Web site: $w$ ww.nj.gov/health/peosh

On-site Consultation for Public Employers

诲Telephone: 609-984-1863 (health) or 609-633-2587 (safety)

Web site: www.state.nj.us/health/eoh/peoshweb/peoshcon.htm 
New Jersey Department of Labor and Workforce Development, Occupational Safety and Health On-Site Consultation Program

This program provides free advice to private businesses on improving safety and health in the workplace and complying with OSHA standards.

萢 Telephone: 609-984-0785

Web site: www.nj.gov/labor/lsse/lsonsite.html

\section{New Jersey State Safety Council}

The New Jersey State Safety Council provides a variety of courses on work-related safety. There is a charge for the seminars.

留Telephone: 908-272-7712.

Web site: $\underline{\text { www.njsafety.org }}$

\section{Internet Resources}

Other useful Internet sites for occupational safety and health information:

- $\mathrm{CDC} / \mathrm{NIOSH}-\underline{w w w . c d c . g o v / n i o s h}$

- USDOL Employment Laws Assistance for Workers and Small Businesses - $\underline{w w w . d o l . g o v / e l a w s}$

- National Safety Council - www.nsc.org

- NJDOH FACE reports - www.nj.gov/health/surv/face/index.shtml

- CDC/NIOSH FACE - www.cdc.gov/niosh/face/faceweb.html

- OSHA - www.osha.gov

- ANSI - www.ansi.org

\section{REFERENCES}

1. Job Hazard Analysis. US Department of Labor Publication \# OSHA-3071, 1998 (revised). USDOL, OSHA Publications, PO Box 37535, Washington DC 20013-7535

2. 29 CFR 1910.176(b); Handling materials_-general; Secure Storage. 


\section{Fatality Assessment and Control Evaluation (FACE) Project \\ Investigation \# 15-NJ-07}

This report was prepared by staff members of the New Jersey Department of Health's Occupational Health Surveillance Unit. The goal of FACE is to prevent fatal work-related injuries by studying the work environment, the worker, the task, the tools the worker was using, the energy exchange resulting in the fatal injury, and the role of management in controlling how these factors interact. FACE gathers information from multiple sources that may include interviews of employers, workers, and other investigators; examination of the fatality site and related equipment; and reviewing OSHA, police, and medical examiner reports, employer safety procedures, and training plans. The FACE program does not determine fault or place blame on employers or individual workers. Findings are summarized in narrative investigation reports that include recommendations for preventing similar events. All names and other identifiers are removed from FACE reports and other data to protect the confidentiality of those who participate in the program.

NIOSH-funded state-based FACE Programs include: California, Iowa, Kentucky, Massachusetts, Michigan, New Jersey, New York, Oregon, and Washington. Please visit the NJ FACE Web site at www.nj.gov/health/surv/face/index.shtml or the CDC/NIOSH FACE Web site at www.cdc.gov/niosh/face/faceweb.html for more information.

The NJ FACE Project is supported by the Centers for Disease Control and Prevention (CDC). The contents of this report are solely the responsibility of the authors and do not necessarily represent the official views of the CDC.

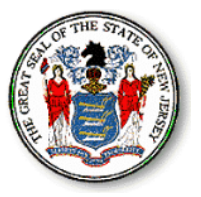

Public Health Services Branch Division of Epidemiology, Environmental and Occupational Health Occupational Health Surveillance Unit (609) 826-4984 nj.gov/health/surv/face/index.shtml 